
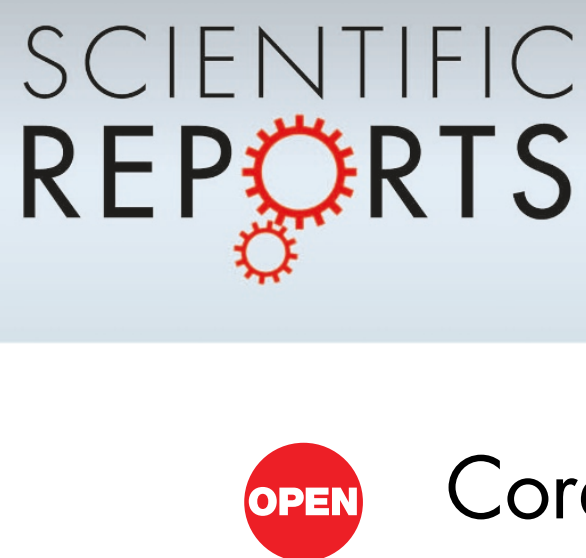

\title{
Core-shell silicon nanowire solar cells
}

\author{
M. M. Adachi ${ }^{1,2}$, M. P. Anantram ${ }^{3}$ \& K. S. Karim ${ }^{1,2}$
}

SUBJECT AREAS:

SOLAR CELLS

NANOWIRES

SOLAR ENERGY AND PHOTOVOLTAIC

TECHNOLOGY

ELECTRICAL AND ELECTRONIC ENGINEERING

Received

10 November 2012

Accepted

26 February 2013

Published

26 March 2013

Correspondence and requests for materials should be addressed to M.M.A. (mmadachi@ alumni.uwaterloo.ca)
${ }^{1}$ Department of Electrical and Computer Engineering, ${ }^{2}$ Waterloo Institute for Nanotechnology, University of Waterloo, Waterloo, Ontario N2L 3G1, Canada, ${ }^{3}$ Department of Electrical Engineering, University of Washington, Seattle, Washington 98105-2500, USA.

Silicon nanowires can enhance broadband optical absorption and reduce radial carrier collection distances in solar cell devices. Arrays of disordered nanowires grown by vapor-liquid-solid method are attractive because they can be grown on low-cost substrates such as glass, and are large area compatible. Here, we experimentally demonstrate that an array of disordered silicon nanowires surrounded by a thin transparent conductive oxide has both low diffuse and specular reflection with total values as low as $<4 \%$ over a broad wavelength range of $400 \mathrm{~nm}<\lambda<650 \mathrm{~nm}$. These anti-reflective properties together with enhanced infrared absorption in the core-shell nanowire facilitates enhancement in external quantum efficiency using two different active shell materials: amorphous silicon and nanocrystalline silicon. As a result, the core-shell nanowire device exhibits a short-circuit current enhancement of $15 \%$ with an amorphous Si shell and $26 \%$ with a nanocrystalline $\mathrm{Si}$ shell compared to their corresponding planar devices.

olar power, harvested by photovoltaic devices, is an abundant, clean, and renewable energy source. In recent years, nanowires have been investigated for improving optical absorption ${ }^{1-10}$ and collection efficiency ${ }^{11,12}$ in photovoltaic devices while using less material than planar devices. Bottom up grown nanowires, usually by the vapor-liquid-solid (VLS) method, offer a simple and large area compatible method for synthesizing a dense array of silicon nanowires on low cost glass substrates. This method also facilitates tailoring of the optical properties of the nanowires by independent control of nanowire diameter and length. However, metal catalysts introduced during vapor-liquid-solid (VLS) nanowire growth can significantly degrade carrier collection efficiency $^{2,13}$. A number of attempts have been made to circumvent the effect of catalyst impurities on device performance such as removal of catalyst impurities after nanowire growth by thermal oxidation ${ }^{14}$, or surface passivation by an $\mathrm{Al}_{2} \mathrm{O}_{3}$ film ${ }^{15}$. However, conversion efficiencies of solar cells incorporating bottom-up grown nanowires remain relatively low ${ }^{1-2,14-18}$. Here, we show that disordered Si nanowires surrounded by a thin transparent conductive oxide outer shell exhibit both low broadband diffuse and specular reflectance. Furthermore, core-shell nanowire devices with both an amorphous Si and nanocrystalline Si absorber shell exhibit strong enhancement in external quantum efficiency and short-circuit current compared to planar control devices. All nanowires and thin film Si and electrical contacts are prepared by large-area compatible vacuum processes on glass substrates, making this approach attractive for large-area, low-material cost production.

Si nanowires are incorporated into a core-shell nanowire solar cell as illustrated in Figure 1a. A thin transparent $\mathrm{ZnO}: \mathrm{Al}$ (average radial thickness $=23 \mathrm{~nm}$ ) layer coats the nanowires and acts as a barrier for 1) isolating the nanocluster catalyst introduced during nanowire growth from the active $n-i-p$ shell, and 2) preventing counterdoping of the $\mathrm{n}$-type layer by the $\mathrm{Al}$ back contact ${ }^{19}$. Therefore, the nanowires are not active device absorbers but rather provide high aspect ratio structure to the active $n-i-p$ shell surrounding the nanowire where photogeneration and collection of photogenerated carriers occurs. Two devices are fabricated, one with an amorphous Si absorber shell and one with a nanocrystalline Si absorber shell. The results of each device are discussed separately. Nanocrystalline $\mathrm{Si}$ is a stable thin film material which has an indirect bandgap close to that of crystalline Si $(\sim 1.1 \mathrm{eV})^{20}$. Furthermore, nanocrystalline Si absorbs infrared light, and can therefore be used in a tandem cell configuration with amorphous Si for increasing total broadband absorption. However, like crystalline Si, nanocrystalline Si has an indirect bandgap so light absorption is weak in thin films, particularly at infrared wavelengths. Therefore, a light trapping mechanism is essential for maximizing device performance in nanocrystalline $\mathrm{Si}$ devices. The incident light enters the device through a thin $\mathrm{ZnO}$ : Al top contact. The planar control cell which has an intrinsic thickness $t$, as illustrated in Figure $1 \mathrm{~b}$, is used for comparison.

\section{Results}

Amorphous Si nanowire shell solar cells. A highly dense array of Si nanowires was grown by VLS method on an Al coated glass substrate as shown in the Secondary Electron Microscopy (SEM) image in Figure 2a. The average 

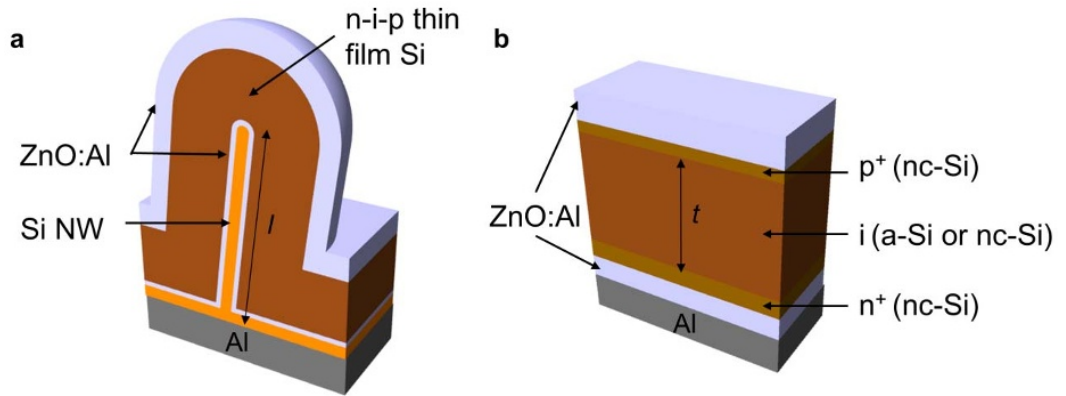

Figure $1 \mid$ Core-shell Si nanowire device architecture. (a) 3D cross-section illustration of the core-shell Si nanowire (NW) device structure. The active device region is the radial $\mathrm{n}-\mathrm{i}-\mathrm{p}$ thin film Si shell surrounding the nanowire. Light is incident through the aluminum doped $\mathrm{ZnO}$ ( $\mathrm{ZnO}$ : $\mathrm{Al}$ ) transparent conductive oxide top contact. The intrinsic (i) region is amorphous $\mathrm{Si}$ (a-Si) or nanocrystalline $\mathrm{Si}$ (nc-Si). (b) 3D cross-section illustration of a planar control cell.

nanowire length is $525 \mathrm{~nm}$, and the average nanowire diameter is $20 \mathrm{~nm}$. The nanowires after coating by a thin $\mathrm{ZnO}:$ Al barrier layer is shown in Figure $2 \mathrm{~b}$, and the final device structure consisting of a radial $\mathrm{n}$-i-p shell and $\mathrm{ZnO}: \mathrm{Al}$ top contact is shown at a $45^{\circ}$ tilt-view in Figure $2 \mathrm{c}$ and as a cross-section $\left(75^{\circ}\right.$ tilt-view) in Figure $2 \mathrm{~d}$. The average total diameter of the $n$-i-p radial nanowire device is $360 \mathrm{~nm}$ without top $\mathrm{ZnO}$ : Al contact and $440 \mathrm{~nm}$ with top $\mathrm{ZnO}$ : Al contact. The $\mathrm{ZnO}$ : Al top contact has an average thickness of $74 \mathrm{~nm}$ at the top of the nanowires (Figure 2d) and thinner along the vertical sidewalls. Due to the higher surface area of the nanowires and thin top contact layer, Ag gridlines were necessary to decrease the series resistance of the top contact.

The total (specular and diffuse) reflectance of a core-shell nanowire a-Si solar cell and a planar a-Si solar cell is shown in Figure 3a. The thickness of the $\mathrm{ZnO}: \mathrm{Al}$ contact for the planar device was measured to be $75 \mathrm{~nm} \pm 5 \mathrm{~nm}$, chosen to satisfy the quarter-wavelength minimum reflectance condition of $d n=\lambda / 4$ for incident light normal to the substrate, where $d$ is the thickness of the film and $n$ is the index of refraction of the antireflective coating $(\mathrm{n} \sim 2.0 \text { for } \mathrm{ZnO}: \mathrm{Al})^{21}$. The total reflectance of the planar device exhibits a minimum of $0.5 \%$ at $\lambda$ $=550 \mathrm{~nm}$, but is much higher at short ( $37 \%$ at $\lambda=360 \mathrm{~nm})$ and long wavelengths ( $>60 \%$ for $\lambda>670 \mathrm{~nm}$ ). In comparison, the core-shell
NW device structure strongly suppresses broadband reflectance. The total reflectance of the core-shell nanowire structure is $<4 \%$ over a broad wavelength interval of $400 \mathrm{~nm}<\lambda<650 \mathrm{~nm}$ where absorption in a-Si is most efficient, and exceeds $10 \%$ only for $\lambda>700 \mathrm{~nm}$. Note that the transmission through $\mathrm{Al} /$ glass was measured to be zero for the entire spectrum so no light is lost to transmission.

The external quantum efficiency, defined as the percentage of electrons collected per incident photon measured under short-circuit conditions, of the core-shell nanowire solar cell and that of the planar a-Si solar cell is shown in Figure 3b. The nanowire device exhibits higher external quantum efficiency (EQE) than the planar device over most of the wavelength spectrum. The higher EQE can be attributed to lower reflectance losses (Figure 3a) in the nanowire device and enhanced infrared absorption caused by multiple scattering within the nanowire shell. The EQE enhancement ratio between the nanowire device and planar device (i.e., $\mathrm{EQE}_{\mathrm{NW}} / \mathrm{EQE}_{\text {planar }}$ ) is as high as 3.2 at $\lambda=700 \mathrm{~nm}$. The core-shell nanowire device has a lower EQE than the planar device only within the wavelength interval $\lambda=500 \mathrm{~nm}$ to $600 \mathrm{~nm}$, which is caused by higher absorption loss in the $\mathrm{p}^{+} \mathrm{Si}$ shell in the nanowire device. The nanowire device required a $50 \%$ longer $\mathrm{p}^{+} \mathrm{Si}$ deposition than in the planar device to sufficiently cover the nanowire side-walls for efficient charge collection leading to higher absorption
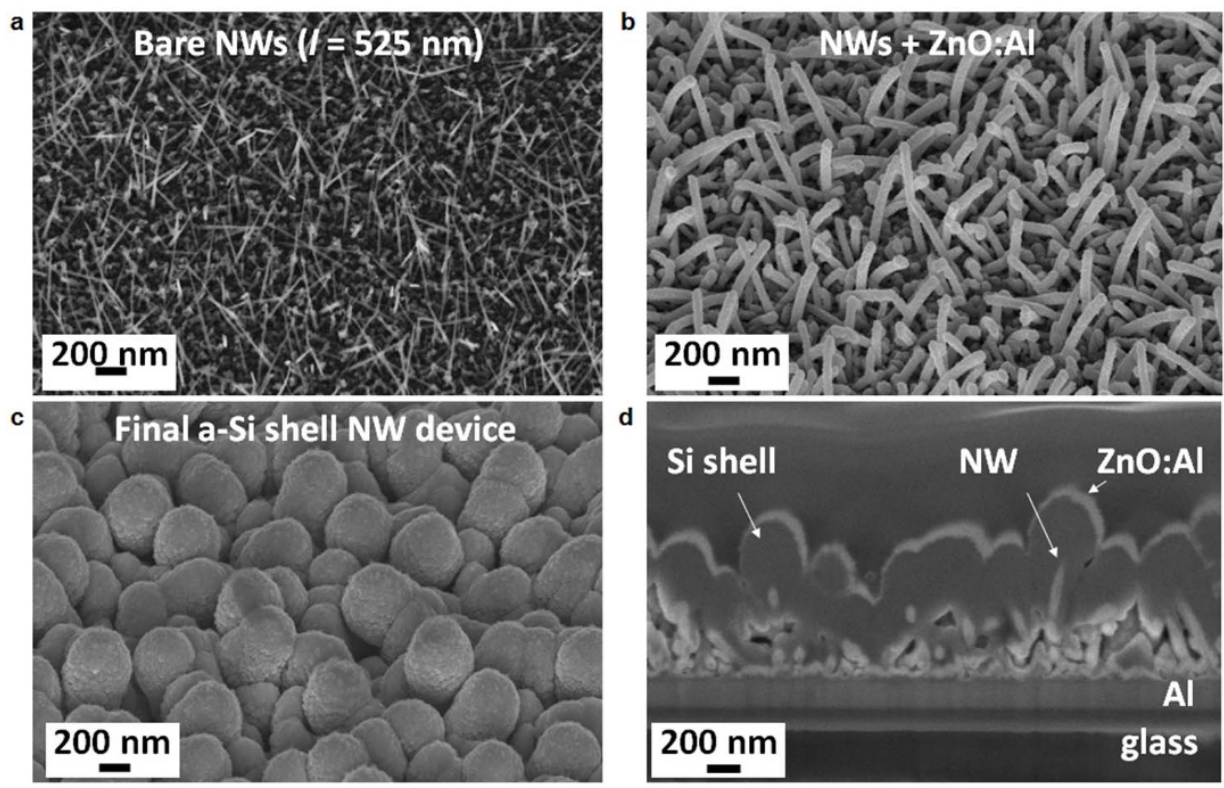

Figure $2 \mid$ Amorphous Si nanowire shell solar cells at different stages of fabrication. (a) SEM image ( $45^{\circ}$ tilt) of an array of bare Si nanowires with an average nanowire length of $l=525 \mathrm{~nm}$ and average nanowire diameter of $20 \mathrm{~nm}$. (b) SEM image ( $45^{\circ}$ tilt) of an array of nanowires (NWs) surrounded by a thin layer of $\mathrm{ZnO}: \mathrm{Al}$ (b). (c) SEM image $\left(45^{\circ}\right.$ tilt) and (d) cross-sectional SEM ( $75^{\circ}$ tilt) of the final n-i-p radial nanowire solar cell with $\mathrm{ZnO}: \mathrm{Al}$ top contact. The intrinsic nanowire shell material is amorphous $\mathrm{Si}$ and the average diameter of the total device structure is $440 \mathrm{~nm}$ with $\mathrm{ZnO}: \mathrm{Al}$ top contact. 


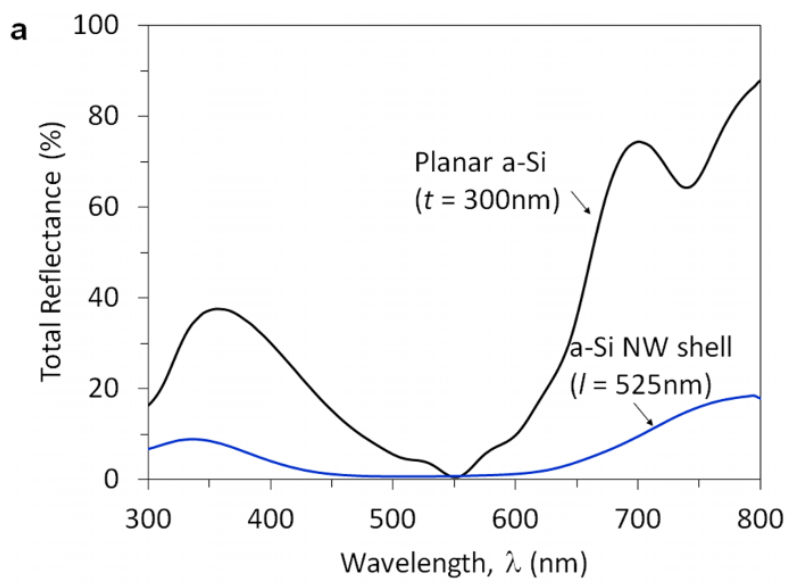

b
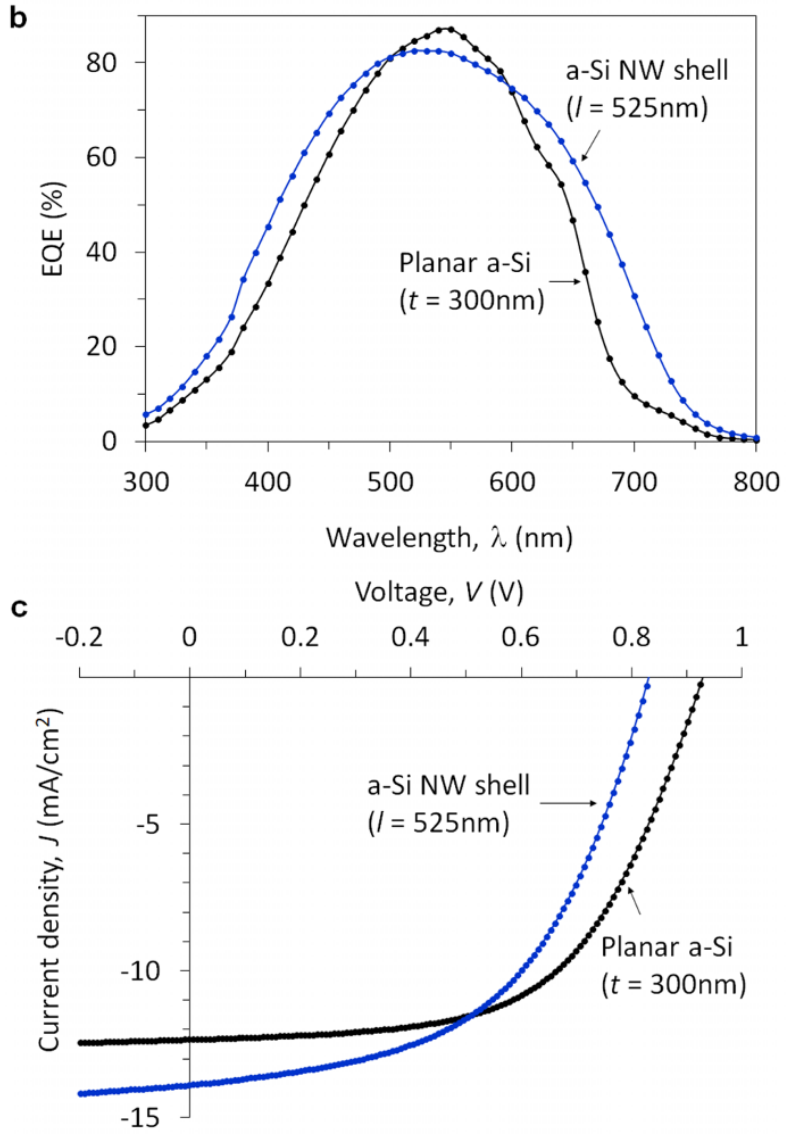

Figure 3 Performance of amorphous Si nanowire shell solar cells. (a) Total (specular and diffuse) reflectance of an amorphous $\mathrm{Si}(\mathrm{a}-\mathrm{Si})$ nanowire (NW) shell solar cell and a planar a-Si control device. The total reflectance of the amorphous Si nanowire shell device is $<4 \%$ in the wavelength interval of $400 \mathrm{~nm}<\lambda<650 \mathrm{~nm}$ and exceeds $10 \%$ only at $\lambda>$ $700 \mathrm{~nm}$. (b) External quantum efficiency (EQE) spectra at zero voltage bias of the amorphous Si nanowire shell solar cell (average nanowire length $l=$ $525 \mathrm{~nm}$ ). The nanowire device demonstrates higher EQE than the planar device for all wavelengths other than the interval $\lambda=500 \mathrm{~nm}-600 \mathrm{~nm}$. (c) $J-V$ characteristic under AM 1.5 global illumination $\left(100 \mathrm{~mW} / \mathrm{cm}^{2}\right)$ of the amorphous Si nanowire shell solar cell. The nanowire device has a $J_{s c}=$ $13.9 \mathrm{~mA} / \mathrm{cm}^{2}, V_{o c}=0.830 \mathrm{~V}, F F=52.4 \%$, and conversion efficiency of $\eta$ $=6.0 \%$. The device characteristics of the planar a-Si device is $J_{s c}=$ $12.1 \mathrm{~mA} / \mathrm{cm}^{2}, V_{o c}=0.932 \mathrm{~V}, F F=57.9 \%$, and $\eta=6.5 \%$. losses in the $\mathrm{p}^{+}$region than the planar device. One method to increase EQE further is to improve conformal coverage of the $\mathrm{p}^{+} \mathrm{Si}$ shell around the nanowires, facilitating the use of a thinner $\mathrm{p}^{+} \mathrm{Si}$ shell.

The current density $(J)$ versus voltage $(V)$ measurements under solar simulator spectrum (AM 1.5 global) illumination of the a-Si nanowire shell device and planar a-Si control device are shown in Figure $3 \mathrm{c}$. The nanowire device has a short circuit current density $\left(J_{s c}\right)$ of $13.9 \mathrm{~mA} / \mathrm{cm}^{2}$, open circuit voltage $\left(V_{o c}\right)$ of $0.830 \mathrm{~V}$, fill factor $(F F)$ of $52.4 \%$, and conversion efficiency $(\eta)$ of $6.0 \%$. In comparison, the device characteristics of the planar a-Si device was $J_{s c}=12.1$ $\mathrm{mA} / \mathrm{cm}^{2}, V_{o c}=0.932 \mathrm{~V}, F F=57.9 \%$, and $\eta=6.5 \%$. The short circuit current in the nanowire device corresponds to a $15 \%$ improvement than that of the planar device. The $J_{s c}$ measured by $J-V$ measurements agree to within 3\% with the $J_{s c}$ determined from the integrated EQE spectra in Figure $3 \mathrm{~b}$, thus verifying the calibration of the measurement. Further discussion on the device performance of the nanowire device is presented in the Discussion section.

Nanocrystalline Si nanowire shell solar cells. The device architecture of the nanocrystalline $\mathrm{Si}$ nanowire shell device is the same as that of the amorphous Si nanowire shell device (Figure 1a). Arrays of two different average nanowire lengths, $l=525 \mathrm{~nm}$ and $800 \mathrm{~nm}$, are incorporated into core-shell devices. The average diameter (with $\mathrm{ZnO}: \mathrm{Al}$ contact) of the nanowire tip is $574 \mathrm{~nm}$ for $l$ $=525 \mathrm{~nm}$, and $533 \mathrm{~nm}$ for $l=800 \mathrm{~nm}$ (Supp. Figure S3d).

The total reflectance spectra of nanocrystalline Si nanowire shell solar cells with two different average nanowire lengths of $525 \mathrm{~nm}$ and $800 \mathrm{~nm}$, and that of a planar nanocrystalline Si solar cell are shown in Figure 4a. The planar nanocrystalline Si device shows high total reflectance with values of up to $24 \%$ at a short wavelength of $\lambda=$ $350 \mathrm{~nm}$ and exceeds $40 \%$ for $\lambda>700 \mathrm{~nm}$. In comparison, the total reflectance of both nanowire devices is $\leq 6 \%$ over the wavelength range of $\lambda=400 \mathrm{~nm}$ to $650 \mathrm{~nm}$ which is slightly higher than that of the amorphous Si shell reflectance in Figure 3a. The higher reflectance of the nanocrystalline Si nanowire shell devices can be attributed to less spacing between nanowires for the nanocrystalline $\mathrm{Si}$ shell device. More specifically, for the same average nanowire length $(l=525 \mathrm{~nm})$, the average diameter of the nanocrystalline Si shell and amorphous Si shell devices without a top contact was $475 \mathrm{~nm}$ and $360 \mathrm{~nm}$, respectively. The reflectance of the nanocrystalline Si nanowire shell devices exceeds $10 \%$ only for $\lambda>700 \mathrm{~nm}$ at which absorption in nanocrystalline $\mathrm{Si}$ is weak.

The external quantum efficiency spectra of nanocrystalline $\mathrm{Si}$ nanowire shell solar cells with an average length of $525 \mathrm{~nm}$ and $800 \mathrm{~nm}$ are shown in Figure 4b. The EQE of a planar solar cell consisting of a $1 \mu \mathrm{m}$ nanocrystalline Si intrinsic layer is also shown for comparison. Both core-shell nanowire devices exhibit higher EQE than the planar device over nearly the entire wavelength spectrum $(\lambda=300-1000 \mathrm{~nm})$. Furthermore, the core-shell nanowire devices with a longer nanowire length $(l=800 \mathrm{~nm})$ exhibit higher EQE than that of the shorter nanowire length $(l=525 \mathrm{~nm})$ over all wavelengths, particularly at longer wavelengths between $500-900 \mathrm{~nm}$.

The $J-V$ curves of nanocrystalline Si nanowire shell solar cells with lengths of $525 \mathrm{~nm}$ and $800 \mathrm{~nm}$ under AM 1.5 global illumination $\left(100 \mathrm{~mW} / \mathrm{cm}^{2}\right)$ are shown in Figure $4 \mathrm{c}$. The $J-V$ curve of the planar nanocrystalline $\mathrm{Si}$ solar cell with an intrinsic nanocrystalline Si layer thickness of $1 \mu \mathrm{m}$ is shown for reference for which $J_{s c}=13.2$ $\mathrm{mA} / \mathrm{cm}^{2}, F F=54.8 \%, V_{o c}=0.42 \mathrm{~V}$, and $\eta=3.0 \%$. Both nanocrystalline Si nanowire shell solar cells show strong improvement in $J_{s c}$, with respect to the planar device: $14.9 \mathrm{~mA} / \mathrm{cm}^{2}$ for $l=525 \mathrm{~nm}$ and $16.6 \mathrm{~mA} / \mathrm{cm}^{2}$ for $l=800 \mathrm{~nm}$. These values correspond to an enhancement in $J_{s c}$ of $13 \%$ and $26 \%$, respectively. The other device parameters of the shorter nanocrystalline Si nanowire $(l=525 \mathrm{~nm})$ shell solar cell are $V_{o c}=0.39 \mathrm{~V}$ and $F F=50.3 \%$, resulting in a conversion efficiency of $\eta=2.9 \%$. For the longer nanocrystalline Si nanowire shell device $(l=800 \mathrm{~nm}), V_{o c}=0.37 \mathrm{~V}, F F=38.0 \%$, and $\eta=2.3 \%$. 


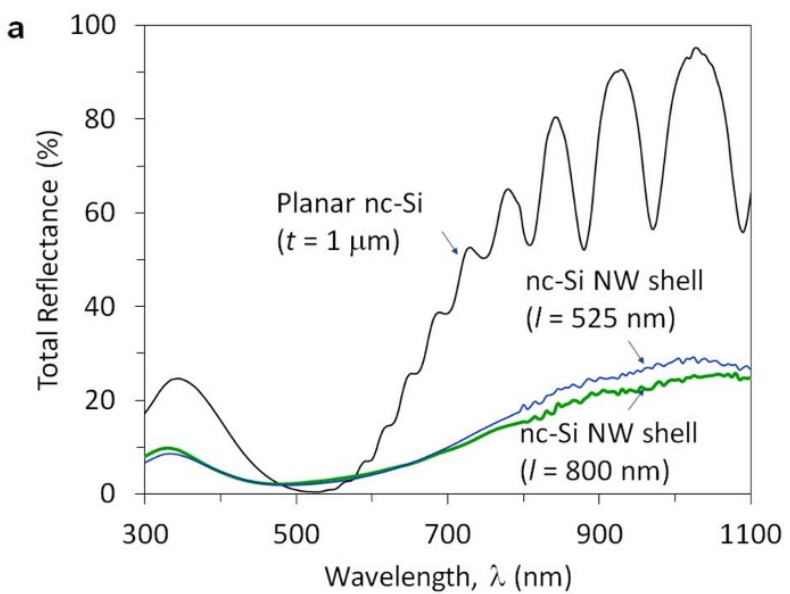

b
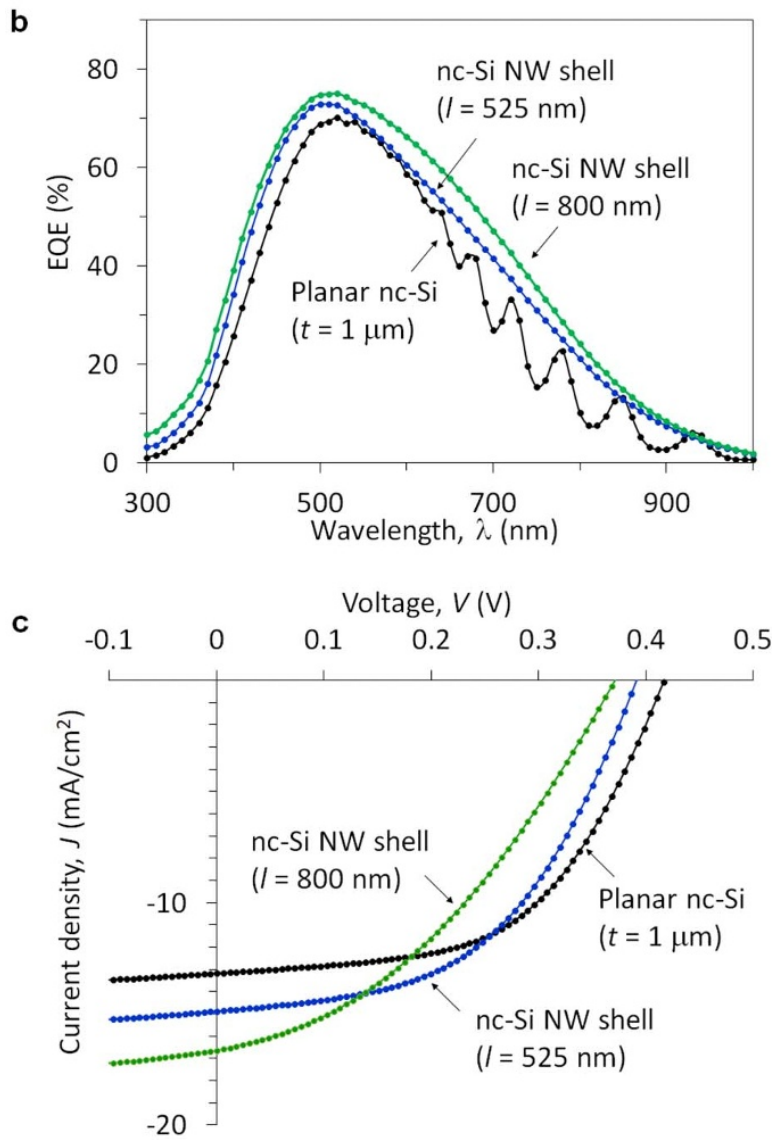

Figure 4 | Performance of nanocrystalline Si nanowire shell solar cells. (a) Total (specular and diffuse) reflectance of nanocrystalline $\mathrm{Si}$ (nc-Si) nanowire (NW) shell solar cells with an average nanowire length 1 of $525 \mathrm{~nm}$ and $800 \mathrm{~nm}$, and a planar nc-Si control device. (b) External quantum efficiency (EQE) spectra of the nanocrystalline Si nanowire shell solar cells. The core-shell solar cell with the longest nanowires $(l=$ $800 \mathrm{~nm}$ ) demonstrates the highest quantum efficiency at nearly all wavelengths ( $\lambda=300$ to $1000 \mathrm{~nm}$ ). (c) $J-V$ curves under AM 1.5 global illumination $\left(100 \mathrm{~mW} / \mathrm{cm}^{2}\right)$ of the nanocrystalline Si nanowire shell solar cells.

\section{Discussion}

Figure $3 \mathrm{a}$ and $4 \mathrm{a}$ shows the total reflectance of core-shell nanowire solar cells with two different shell materials, amorphous Si and nanocrystalline $\mathrm{Si}$, respectively. One of the drawbacks of bare disordered nanowires is that they have high diffuse reflectance at high photon energies (e.g. $33 \%$ at $2.2 \mathrm{eV}$ ) due to diffuse light scattering 8 . The total reflectance spectra in Figure 3a and 4a experimentally demonstrates that low diffuse reflectance can be achieved in disordered $\mathrm{Si}$ nanowires when coated with a suitably thin transparent oxide layer. The $\mathrm{ZnO}$ : Al shell acts as an anti-reflective coating with an intermediate refractive index between that of air and $\mathrm{Si}(\mathrm{n} \sim 2$ for $\mathrm{ZnO}: \mathrm{Al}$ ), reducing diffuse light scattering by the nanowires. In fact, a theoretical study of a single core-shell nanowire consisting of an amorphous Si nanowire coated with a thin dielectric has shown that this core-shell structure can lead to significant absorption enhancement compared to an amorphous $\mathrm{Si}$ nanowire on its own ${ }^{22}$. The oxide shell acts as an anti-reflective coating with optimal anti-reflective properties when the thickness of this layer is $70 \mathrm{~nm}$. In our study, the $\mathrm{ZnO}$ : Al thickness at the top of core-shell nanowires is measured to be on average $74 \mathrm{~nm}$ facilitating the low reflectance observed in Figures $3 \mathrm{a}$ and $4 \mathrm{a}$.

These anti-reflective properties and enhanced infrared absorption from multiple scattering facilitates the enhancement in EQE shown in Figure $3 \mathrm{~b}$ and $4 \mathrm{~b}$. Note that that the EQE of the nanowire device was measured at zero bias, corresponding to the higher $J_{s c}$ observed in Figures $3 \mathrm{c}$ and $4 \mathrm{c}$, but the overall conversion efficiencies in both the amorphous $\mathrm{Si}$ shell and nanocrystalline $\mathrm{Si}$ shell devices are lower than the planar devices due to a drop in $V_{o c}$ and FF. A drop in $V_{o c}$ and FF has also been observed in p-n junction nanowire solar cells fabricated from mono-crystalline $\mathrm{Si}^{3,23}$. In this case, the drop in Voc and FF can be attributed to a decrease in minority-carrier lifetime caused by faster surface recombination in the nanowire devices than planar devices. Similarly, in a p-i-n thin film Si device architecture, $V_{o c}$ is highly dependent on carrier recombination at the p/intrinsic region interface or within the intrinsic region near this interface ${ }^{24}$. Therefore, the drop in $V_{o c}$ observed in Figure $3 \mathrm{c}$ and $4 \mathrm{c}$ can be attributed to higher recombination at the $\mathrm{p} /$ intrinsic interface due to the high surface area of the core-shell nanowire devices. One method to minimize the drop in $V_{o c}$ is to reduce the surface area by growing sparser nanowires with larger diameter $\mathrm{ZnO}$ : $\mathrm{Al}$ cores or by growing shorter nanowires. Alternatively, recombination at the $\mathrm{p} / \mathrm{i}$ interface can be reduced by introducing a thin graded p-type interface layer between the $\mathrm{p}$ and intrinsic regions $\mathrm{s}^{25}$.

The lower fill factor of the nanowire device can be attributed to non-conformal coverage of the $\mathrm{n}^{+}$shell, particularly near the base of the nanowires, due to the close proximity of nanowires to each other (Figure 2d). Methods to improve fill factor include tailoring the deposition conditions of the $\mathrm{n}+, \mathrm{i}$, and $\mathrm{p}^{+} \mathrm{Si}$ shell layers for better conformal growth and slightly increasing spacing between nanowires to reduce shadowing effects between nanowires during shell growth. The drop in FF in the nanowire shell devices (Figure $3 \mathrm{c}$ and 4c) can also be attributed to high series resistance in the top $\mathrm{ZnO}: \mathrm{Al}$ contact (particularly for the longer nanowires, $l=800 \mathrm{~nm}$ ). The high surface area of the nanowires increases the sheet resistance of the top contact, limiting the use of the long nanowires. For example, the top $\mathrm{ZnO}$ : Al sheet resistance (without metals grids) increased from 88 $\Omega /$ sq. for the planar amorphous Si device to $300 \Omega /$ sq. for the amorphous Si nanowire shell device. Therefore, reducing the resistivity of the top contact would facilitate the use of longer nanowires for further increasing optical absorption. One method to lower the top contact sheet resistance, while maintaining high optical transmission, is to coat the top contact with a network of $\mathrm{Ag}$ nanowires ${ }^{26}$.

In conclusion, we have incorporated disordered Si nanowires into a core-shell device architecture using two different active shell materials: amorphous $\mathrm{Si}$ and nanocrystalline $\mathrm{Si}$. For both devices, the core-shell nanowire devices exhibit low total reflectance leading to enhancement in external quantum efficiency over a wide range of wavelengths compared to a planar control device. As a result, the core-shell nanowire device with amorphous Si absorber shell exhibited a $J_{s c}=13.9 \mathrm{~mA} / \mathrm{cm}^{2}$ compared to $12.1 \mathrm{~mA} / \mathrm{cm}^{2}$ of the planar 
device. Similarly, the nanowire device with nanocrystalline $\mathrm{Si}$ absorber shells showed a $J_{s c}$ of up to $16.6 \mathrm{~mA} / \mathrm{cm}^{2}$ compared to $J_{s c}=13.2 \mathrm{~mA} / \mathrm{cm}^{2}$ of the planar device. Furthermore, the external quantum efficiency of the nanocrystalline Si nanowire shell solar cell extends the solar spectrum utilization to wavelengths of up to $1000 \mathrm{~nm}$, making it promising as the bottom cell in amorphous $\mathrm{Si} /$ nanocrystalline $\mathrm{Si}$ tandem radial junction nanowire solar cell. All nanowires and $\mathrm{Si}$ shells were grown by conventional large area PECVD methods on glass substrates. Therefore, core-shell nanowire solar cells are an exciting alternate to conventional light trapping techniques (i.e. surface texturing) for large area photovoltaics. Furthermore, the ability to tailor the optical properties of the nanowire device via controlling the nanowire diameter, length, and density makes them attractive for other large area applications such as image sensors for medical imaging and large area photodetectors.

\section{Methods}

Silicon nanowire preparation. Si nanowires were grown by the Vapour-Liquid-Solid (VLS) technique ${ }^{27}$ in an $\mathrm{rf}$ parallel plate PECVD deposition system ${ }^{10}$. These nanowires were grown on $\mathrm{Al}$ coated Corning Eagle XG glass substrates. The glass substrates were cleaned, first by immersion in an ultrasonic bath containing acetone and then in one containing isopropyl alcohol. Tin (Sn) nanoclusters, formed by depositing a $2 \mathrm{~nm}$ thick Sn film by e-beam evaporation and annealing in vacuum at $400^{\circ} \mathrm{C}$ for 1 hour, were used as the catalyst for nanowire growth. Nanowires were grown using $\mathrm{SiH}_{4}$ source gas diluted in $\mathrm{H}_{2}$ at a pressure of $1400 \mathrm{mTorr}$ and $13.56 \mathrm{Mhz}$ rf plasma density of $16.4 \mathrm{~mW} / \mathrm{cm}^{2}$. A high $\mathrm{H}_{2}$ dilution of $\left[\mathrm{H}_{2}\right] /\left[\mathrm{SiH}_{4}\right]=$ 62 was used to suppress the growth of amorphous $\mathrm{Si}$ and improve nanowire growth uniformity. The nanowires were grown at a substrate temperature of $400^{\circ} \mathrm{C}$ for 15-23 $\mathrm{min}$.

Device preparation. An Al back-contact film was deposited by dc magnetron sputtering and aluminum doped $\mathrm{ZnO}(\mathrm{ZnO}: \mathrm{Al})$ contacts were deposited by rf magnetron sputtering. The active thin film Si layers were fabricated by rf parallel plate PECVD in a cluster tool deposition system. The device structure was glass/ $\mathrm{Al}(170 \mathrm{~nm}) / \mathrm{NWs} / \mathrm{ZnO}: \mathrm{Al}(60 \mathrm{~nm}) / \mathrm{n}^{+} / \mathrm{i} / \mathrm{p}^{+} / \mathrm{ZnO}: \mathrm{Al}(75 \mathrm{~nm})$. The thickness values correspond to those measured on planar substrates. The $\mathrm{n}^{+}$layer thickness was $50 \mathrm{~nm}$ and $\mathrm{p}^{+}$layer thickness was $30 \mathrm{~nm}$ for all planar devices. Two different intrinsic layers were used: a-Si deposited from $\mathrm{SiH}_{4}$ source gas and nanocrystalline $\mathrm{Si}$ deposited from $\mathrm{H}_{2}$ diluted $\mathrm{SiH}_{4}$ gas. The intrinsic amorphous $\mathrm{Si}$ layer was prepared using the same conditions using a pressure of $400 \mathrm{mTorr}$, power density of $7.8 \mathrm{~mW} / \mathrm{cm}^{2}$ and deposition duration of $30 \mathrm{~min}$. for both the nanowire and planar device. The nanocrystalline $\mathrm{Si}$ intrinsic layer was deposited under high pressure (7 Torr), high power density $\left(0.371 \mathrm{~W} / \mathrm{cm}^{2}\right)$, conditions that facilitate high deposition rates $^{28}$. The hydrogen dilution ratio was $\left[\mathrm{H}_{2}\right] /\left[\mathrm{SiH}_{4}\right]=82$ which was near the crystalline/amorphous Si transition point. The deposition time of the intrinsic nanocrystalline Si film was $35 \mathrm{~min}$. for nanowire devices and $70 \mathrm{~min}$. for planar devices. Nanocrystalline $\mathrm{n}^{+}$and nanocrystalline $\mathrm{p}^{+}$shells were deposited by $\mathrm{H}_{2}$ diluted $\mathrm{SiH}_{4}$ with $\mathrm{PH}_{3}$ and $\mathrm{B}_{2} \mathrm{H}_{6}$ dopant gases, respectively. The $\mathrm{n}^{+}$and $\mathrm{p}^{+}$ shell thickness was the same for every nanowire device. The deposition times for the $\mathrm{Al}$ back contact and $\mathrm{ZnO}: \mathrm{Al}$ layers were the same for both the core-shell nanowire device and the planar reference device. The deposition time for both the $\mathrm{n}^{+}$and $\mathrm{p}^{+}$nanocrystalline $\mathrm{Si}$ shells were longer for the nanowire devices than planar devices to improve nanowire side-wall coverage which was required to achieve efficient charge collection. The resulting nanowire sidewall radial thickness was on average $40 \mathrm{~nm}$ for the $\mathrm{n}^{+}$shell and $17 \mathrm{~nm}$ for the $\mathrm{p}^{+}$shell, which was determined from SEM images before and after deposition of each shell. Ag gridlines were deposited by e-beam evaporation to lower series resistance of the top $\mathrm{ZnO}$ : Al layer. In addition, a drop of conductive Ag paste was placed on the grid line to act as a point of contact for measurement probes. The active area defined by the exposed top $\mathrm{ZnO}: \mathrm{Al}$ contact was $0.44 \mathrm{~cm}^{2}$.

Optical characterization. The total reflectance (including both specular and diffuse components) was measured by a Cary 5000 UV-Vis-NIR spectrophotometer equipped with an integrating sphere. The reflectance was calibrated using Labsphere, Inc. Spectralon Diffuse Reference Standards prior to measurements.

Structural characterization. A Leo 1530 field-emission SEM was used for $45^{\circ}$ tilt SEM measurements and a FEI Magellan 400 high-resolution SEM was used for the cross sectional measurement. The cross-sectional sample was prepared using a Zeiss NVision 40 cross-beam instrument to mill a $15 \mu \mathrm{m}$ long slice at the edge of the sample. Carbon was used as a mask to define the location of the ion-beam cut.

Device characterization. The solar cell devices were characterized by external quantum efficiency (EQE) and current density $(J)$-voltage $(V)$ measurements under AM 1.5 global illumination $\left(100 \mathrm{~mW} / \mathrm{cm}^{2}\right)$. External quantum efficiency (EQE) measurements, under zero bias conditions, were taken on a PV
Measurements Inc. quantum efficiency system, calibrated using a $\mathrm{Si}$ photodiode before measurements. $J V$ curves were measured using a Keithley 2400 source meter and solar simulator (ABET Technologies SUN 2000 series) system. A pre-calibrated monocrystalline Si cell was used for calibration. Note that the short-circuit current $\left(J_{s c}\right)$ for each device determined from the integrated EQE measurements agreed within $3 \%$ to that of the $J_{s c}$ measured by the solar simulator measurements.

1. Tsakalakos, L. et al. Silicon Nanowire Solar Cells. Appl. Phys. Lett. 91, 233117-1-3 (2007).

2. Sivakov, V. et al. Silicon Nanowire-Based Solar Cells on Glass: Synthesis, Optical Properties, and Cell Parameters. Nano Lett. 9, 1549-1554 (2009).

3. Garnett, E. \& Yang, P. Light Trapping in Silicon Nanowire Solar Cells. Nano Lett. 10, 1082-1087 (2010).

4. Li, J. et al. Design guidelines of periodic Si nanowire arrays for solar cell application. Appl. Phys. Lett 95, 243113-1-3 (2009).

5. Lin, C. \& Povinelli, M. L. Optical Absorption Enhancement in Silicon Nanowire Arrays with a Large Lattice Constant for Photovoltaic Applications. Opt. Express 17, 19371-19381 (2009).

6. Bao, H. \& Ruan, X. Optical absorption enhancement in disordered vertical silicon nanowire arrays for photovoltaic applications. Opt. Letters 35 (20), 3378-3380 (2010).

7. Lin, C. \& Povinelli, M. L. Optimal design of aperiodic, vertical silicon nanowire structures for photovoltaics. Opt. Express 19 (S5), A1148-A1154 (2011).

8. Muskens, O. L., Rivas, J. G., Algra, R. E., Bakkers, E. P. \& Lagendijk, A. Design of Light Scattering in Nanowire Materials for Photovoltaic Applications. Nano Lett. 8, 2638-2642 (2008).

9. Tsakalakos, L. et al. Strong Broadband Optical Absorption in Silicon Nanowire Films. J. Nanophotonics 01 (01), 013552 (2007).

10. Adachi, M. M., Anantram, M. P. \& Karim, K. S. Optical Properties of CrystallineAmorphous Core-Shell Silicon Nanowires. Nano Lett. 10, 4093-4098 (2010).

11. Law, M., Greene, L. E., Johnson, J. C., Saykally, R. \& Yang, P. Nanowire dyesensitized solar cells. Nature Mat. 4, 455-459 (2005).

12. Kayes, B. M., Atwater, H. A. \& Lewis, N. S. Comparison of the Device Physics Principles of Planar and Radial p-n Junction Nanorod Solar Cells. J. Appl. Phys. 97, 114302-1 (2005).

13. Adachi, M. M. \& Karim, K. S. Fabrication of PECVD grown nip silicon nanowire solar cells. Proc. 35 th IEEE Phot. Spec. Conf. 2010, 003302-003305 (2010).

14. Kendrick, C. E. et al. Radial junction silicon wire array solar cells fabricated by gold-catalyzed vapor-liquid-solid growth. Appl. Phys. Lett. 97, 143108 (2010).

15. Gunawan, O. \& Guha, S. Characteristics of Vapor-Liquid-Solid Grown Silicon Nanowire Solar Cells. Solar Energy Mater. Solar Cells 93, 1388-93 (2009).

16. Perraud, S. et al. Full process for integrating silicon nanowire arrays into solar cells. Sol. Energ. Mat. Sol. C. 93, 1568-1571 (2009).

17. Kuang, Y. K., van der Welf, K. H. M., Houweling, W. Z. S. \& Schropp, R. E. I Nanorod solar cell with an ultrathin a-Si:H absorber layer. Appl. Phys. Lett. 98, 113111 (2011).

18. Cho, J. et al. Sn-catalyzed silicon nanowire solar cells with $4.9 \%$ efficiency grown on glass. Prog. Photovolt: Res. Appl. doi:10.1002/pip.1245 (2012).

19. Haque, M. S., Naseem, H. A. \& Brown, W. D. Interaction of aluminum with hydrogenated amorphous silicon at low temperatures. J. Appl. Phys. 78 (8), 3928-3935 (1994).

20. Shah, A., Torres, P., Tscharner, R., Wyrsch, N. \& Keppner, H. Photovoltaic Technology: The Case for Thin-Film Solar Cells. Science 285, 692-698 (1999).

21. Rech, R. \& Wagner, H. Potential of amorphous silicon for solar cells. Appl. Phys. A 69, 155-167 (1999).

22. Yu, Y., Ferry, V. E., Alivisatos, P. \& Cao, L. Dielectric Core-Shell Optical Antennas for Strong Solar Absorption Enhancement. Nano Lett. 12, 3674-3681 (2012).

23. Peng, K. et al. Aligned Single-Crystalline Si Nanowire Arrays for Photovoltaic Applications. Small 1, 1062-1067 (2005).

24. Hegedus, S. S., Salzman, N. \& Fagen, E. The relation of dark and illuminated diode parameters to the open-circuit voltage of amorphous silicon pin solar cells. J. Appl. Phys. 63 (10), 5126-5130 (1988).

25. Arya, R. R., Catalano, A. \& Oswald, R. S. Amorphous silicon pin solar cells with graded interface. Appl. Phys. Lett. 49, 1089-1091 (1986).

26. Lee, J. Y., Connor, S. T., Cui, Y. \& Peumans, P. Solution-processed metal nanowire mesh transparent electrodes. Nano Lett. 8 (2), 689-692 (2008).

27. Wagner, R. S. \& Ellis, W. C. Vapor-liquid-solid mechanism of single crystal growth. Appl. Phys. Lett. 4 (5), 89 (1964).

28. Rech, B., Roschek, T., Muller, J., Wieder, S. \& Wagner, H. Amorphous and microcrystalline silicon solar cells prepared at high deposition rates using RF (13.56 MHz) plasma excitation frequencies. Sol. Energ. Mat. Sol. C. 66, 267-273 (2001).

\section{Acknowledgments}

The authors thank T. Leung for access to SEM equipment, S. Sivoththaman for access to EQE measurement equipment, M. Collins for access to spectrophotometry measurement equipment, $\mathrm{H}$. Aziz for access to a solar simulator, R. Barber for technical 
support and M. McPherson for proofreading the manuscript. The work of M.M.A. and K.S.K. was supported by NSERC (Natural Science and Engineering Council of Canada), CFI (Canada Foundation for Innovation), and ORF (Ontario Research Fund). The work of M.P.A. was supported by the National Science Foundation under Grant No. 1001174

\section{Author contributions}

M.M.A. designed, fabricated, and characterized all silicon nanowire devices and control devices under the guidance of K.S.K. and M.P.A. The manuscript was prepared by M.M.A. and all authors contributed in discussing and analyzing the results.

\section{Additional information}

Supplementary information accompanies this paper at http://www.nature.com/ scientificreports

Competing financial interests: The authors declare no competing financial interests.

License: This work is licensed under a Creative Commons

Attribution-NonCommercial-NoDerivs 3.0 Unported License. To view a copy of this

license, visit http://creativecommons.org/licenses/by-nc-nd/3.0/

How to cite this article: Adachi, M.M., Anantram, M.P. \& Karim, K.S. Core-shell silicon nanowire solar cells. Sci. Rep. 3, 1546; DOI:10.1038/srep01546 (2013). 